\title{
INTERVENÇÕES GOVERNAMENTAIS RECENTES NOS CARIRIS VELHOS DA PARAÍBA - BRASIL: REFLEXOS NA AGROPECUÁRIA, NA DEGRADAÇÃO DAS TERRAS E NA CIDADANIA
}

\author{
BARTOLOMEU ISRAEL SOUZA ${ }^{1}$ \\ ELIAMIN ELDAN QUEIROZ ROSENDO ${ }^{2}$ \\ DENNYS DA SILVA BIZERRA ${ }^{3}$ \\ Haerte Durgel Araujo Coutinho de $\mathrm{MelO}^{4}$ \\ JoSEILSOM RAMOS DE MEDEIROS ${ }^{5}$ \\ WILLITON ITOZAMIR ${ }^{6}$ \\ Universidade Federal da Paraíba
}

\footnotetext{
${ }^{1}$ Professor Doutor do Departamento de Geociências da Universidade Federal da Paraíba. Contato: bartolomeuisrael@gmail.com.

${ }^{2}$ Mestrando do Programa de Pós-Graduação em Engenharia Urbana e Ambiental da Universidade Federal da Paraíba. Contato: eliamimeldan@ hotmail.com.

3 Discente do Departamento de Geociências da Universidade Federal da Paraíba. Contato: dennysdsb@hotmail.com.

4 Discente do Departamento de Geociências da Universidade Federal da Paraíba. Contato: haertedurgel@hotmail.com.

Universidade Federal da Paraíba/Departamento de Geociências. Contato: joseilsom.ramos@gmail.com.

Universidade Federal da Paraíba/Departamento de Geociências. Contato: geopesquisador@hotmail.com.
} 
Resumo: A desertificação é um tipo de degradação passível de ocorrer nas zonas secas do mundo quando temos o uso excessivo dos recursos naturais, particularmente a supressão intensa da vegetação durante vários anos. No Brasil, a região dos Cariris Velhos da Paraíba tem sido uma das mais atingidas por esse processo, lugar no qual os recentes incentivos governamentais à caprinocultura vêm provocando uma aceleração desse impacto em função do domínio de uma lógica produtivista com bases ambientais pouco sustentáveis - o que pode ser mais bem percebido nos quatro últimos anos de secas acentuadas que estas terras vêm atravessando, com fortes repercussões na caatinga e também na atividade pecuária. Diversas intervenções governamentais têm minimizado os efeitos da desertificação na qualidade de vida da população, entretanto, como elas não são acompanhadas de um plano de geração de trabalho e renda compatíveis com as condições ambientais da região, questiona-se sobre a dependência política que tais ações vêm provocando.

Palavras-chave: Usos dos Solos; Cariris Velhos; Desertificação; Intervenções Governamentais.

\section{RECENT GOVERNMENT INTERVENTIONS IN CARIRIS VELHOS OF PARAÍBA - BRAZIL: IMPACTS ON AGRICULTURE, DEGRADATION OF LAND AND CITIZENSHIP}

Abstract: Desertification is a kind of degradation that is likely to occur in the dry zones of the world, when we have an excessive use of natural resources, mainly through the removal of vegetation over the years. In Brazil, the region of Cariri Velho in Paraiba has been one of the most affected by this process. The government's recent incentives to the raising of goats has led to an acceleration of this impact due to the dominance of an environmentally unsustainable productivist logic,, which can be better seen with the last four years of in sense drought, with strong repercussions in the Caatinga ecosystem, as well as in the cattle industry. Government intervention has mitigated the effects of desertification in the population's quality of life. However, as these are not accompanied by a plan for creating jobs and income compatible with the environmental conditions of the region, we put into question the political dependency created by these measures.

Keywords: Soil Uses; Cariris Velhos; Desertification; Government Intervention.

\section{Introdução}

A região dos Cariris Velhos (também conhecida como Cariri paraibano ou Cariri) se encontra localizada no estado da Paraíba - Brasil (ver Figura 1), sendo relativamente conhecida em nível nacional devido ao domínio dos baixos índices pluviométricos anuais, tidos como os menores do país (cerca de $500 \mathrm{~mm}$ ), os quais estão associados a uma distribuição que se caracteriza pela heterogeneidade temporal e espacial. Tais condições, associadas à presença de temperaturas médias anuais elevadas $\left(27^{\circ} \mathrm{C}\right)$, tornam o déficit hídrico dominante nesta região, assim como as secas que, quando normais, apresentam duração aproximada de oito meses, embora em momentos excepcionais possam exceder em muito esse período. 


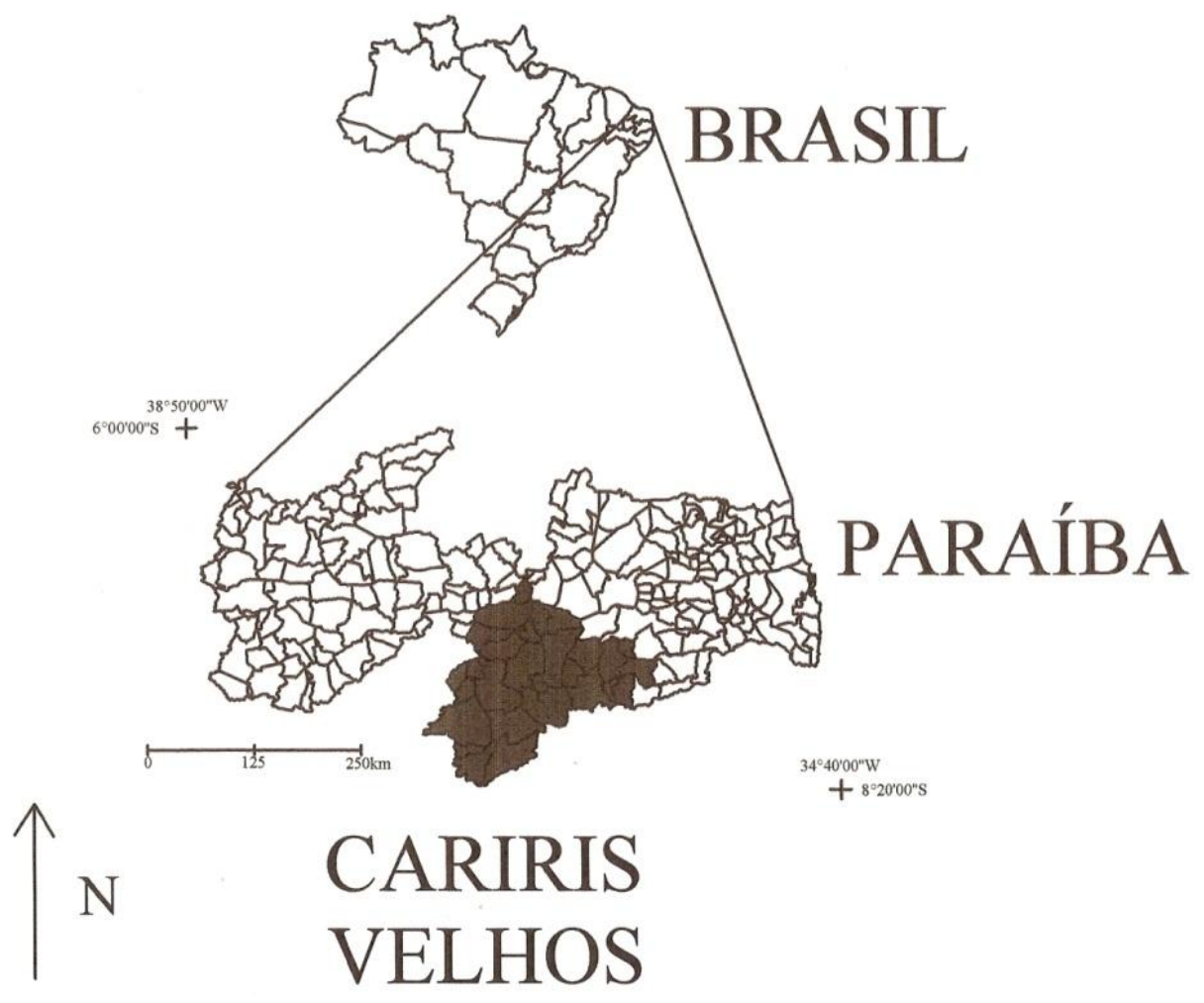

Figura 1: Localização dos Cariris Velhos na Paraíba/Brasil.

Fonte: Elaborado pelos autores.

Quanto à população que habita atualmente a região, há muitos séculos passou a ser o resultado de uma mestiçagem entre povos de origens predominantemente portuguesa e indígena - de diversas tribos. Do ponto de vista histórico, para viverem nesse tipo de ambiente, o saber-fazer relativo à agricultura e à pecuária foi desenvolvido principalmente pelos colonos brancos a partir do século XVII, adaptando gradativamente o seu conhecimento original a uma nova realidade do ponto de vista do quadro físico encontrado, bastante diferente das terras de clima Temperado da Europa e do litoral Tropical quente e úmido do Brasil.

Entretanto, no processo de conquista dessas terras pelos colonos europeus, muitos dos conhecimentos dos índios da região foram assimilados e incorporados, dentre os quais destacamos os que dizem respeito ao aproveitamento de uma grande diversidade de espécies vegetais da caatinga ("mata branca", na língua tupi), formação classificada mais recentemente em nível internacional como um tipo de 
floresta sazonalmente seca (OLIVEIRA FILHO, JARENKOV \& RODAL, 2006), considerada um dos principais biomas do mundo, foco de crescente atenção pelo pouco conhecimento que se tem e pelo fato de estar altamente ameaçada (SANTOS et al., 2012).

Dentre as ameaças presentes, destacamos, em especial, a que passou a ser denominada de desertificação em nível internacional (CCD, 1995) e nacional (BRASIL, 2004), cuja origem e expansão, para muito além da dinâmica natural, está relacionada a uma série de intervenções em que formas de organização do espaço, muitas vezes com o uso excessivo dos solos e da cobertura vegetal, passam a ocorrer sem que os cuidados necessários e suficientes à conservação e à preservação desses recursos sejam tomados.

Este artigo pretende discutir a situação do uso das terras no Cariri, particularmente em sua fase mais atual, assim como a sua repercussão enquanto intensificador do processo de desertificação, em que as intervenções governamentais têm exercido papel fundamental. Pretende-se, assim, contribuir para a compreensão desse tipo de degradação na região, considerada um exemplo do que em grande parte vem sendo desenvolvido historicamente no semiárido brasileiro, analisando a questão, principalmente, enquanto consequência de decisões políticas que foram tomadas em nível nacional, e estabelecendo o quadro ambiental e econômico dominante.

\section{Evolução recente da desertificação nos Cariris Velhos}

Embora de ocorrência muito antiga, a desertificação somente passou a ser reconhecida como um tipo de degradação a partir da década de 1940, com as observações de Aubréville (1949) efetuadas na África, recebendo atenção internacional a partir da década de 1970 e, finalmente, sendo definida oficialmente pela Organização das Nações Unidas (ONU) no início da década de 1990 como “(...) a degradação da terra nas zonas áridas, semi-áridas e subúmidas secas, resultante de vários factores, incluindo as variações climáticas e as actividades humanas" (CCD, 1995).

A degradação da terra, por sua vez, é entendida pela ONU como a diminuição ou perda da produtividade biológica ou econômica e da complexidade das áreas agrícolas, pastagens e florestas, devido à forma como ocorre a utilização das terras, tendo como consequência a erosão do solo, a qual é acompanhada da sua deterioração física, química e biológica ou econômica, assim como da destruição da vegetação por períodos prolongados (CCD, 1995).

Partimos do princípio de que, embora possa ser causada por diversas ações, a retirada maciça da vegetação é a principal desencadeadora da desertificação. Nesse sentido, para identificar se uma área está passando por tal processo, a análise quantitativa e qualitativa dos recursos vegetais é parte essencial desse tipo de 
investigação. Sendo assim, faz-se necessário o reconhecimento de possíveis mudanças na área ocupada pela cobertura vegetal e na diversidade das espécies ocorrentes, tanto em nível espacial como temporal.

Em se tratando do semiárido brasileiro, a extração da vegetação para diversos fins é uma atividade secular ainda hoje muito praticada, tanto para atender às necessidades domésticas como as industriais, particularmente enquanto fonte energética, mas também na construção de cercas entre as propriedades, o que vem acarretando sérios impactos ambientais nessa região.

Com base nessas premissas, para analisar a evolução recente da desertificação nos Cariris da Paraíba nos apoiamos no trabalho de Souza, Suertegaray e Lima (2011), até o momento o único que contempla o processo em toda essa região. $\mathrm{O}$ trabalho em destaque foi realizado com base em observações de campo e análise de imagens de satélite, com um olhar especialmente voltado à vegetação, obtendo-se o resultado que pode ser visto a seguir, na Figura 2, na qual temos a situação mais atual da desertificação na região pesquisada, relativa aos anos 2005/2006.

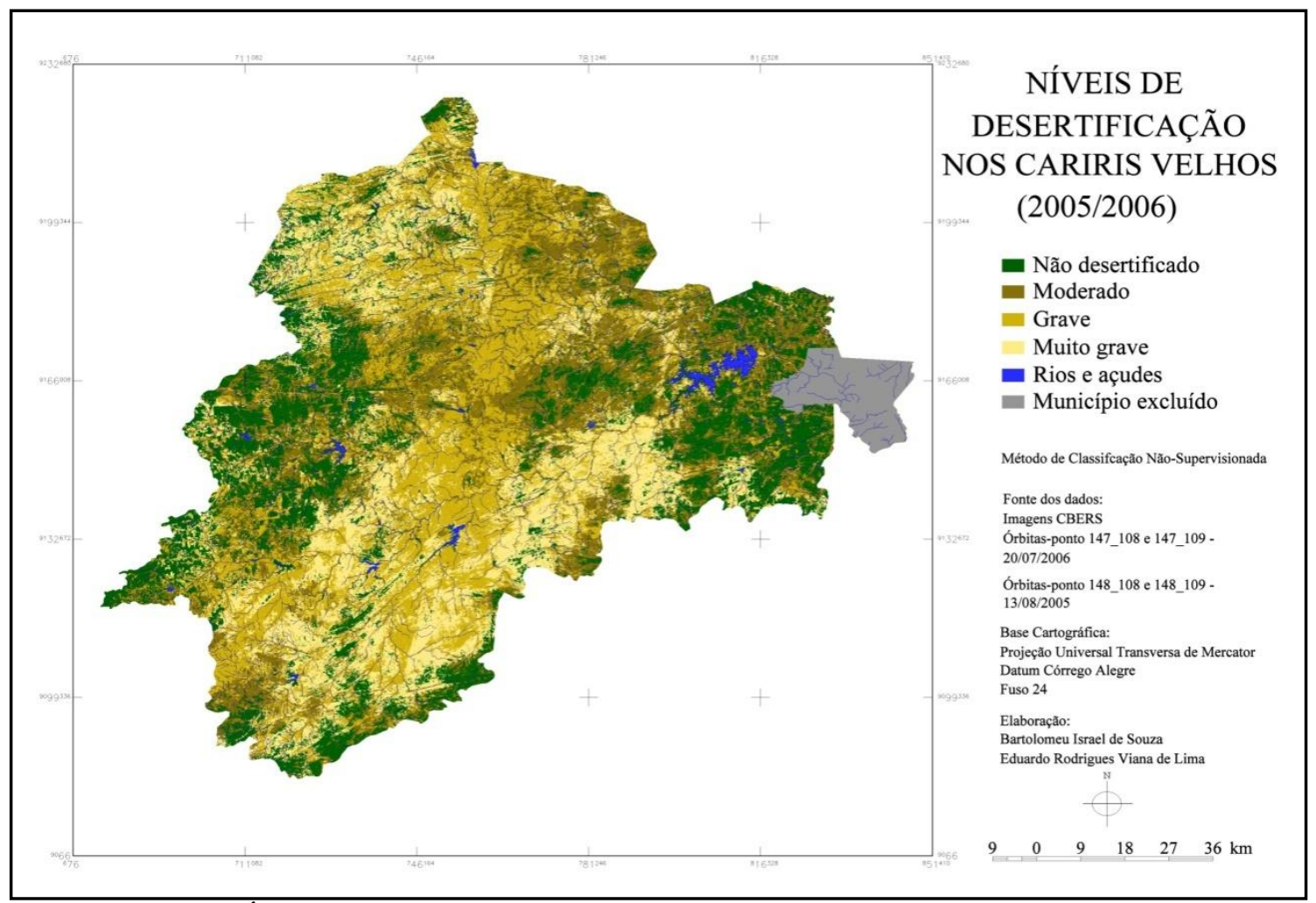

Figura 2: Áreas desertificadas no Cariri em 2005/2006.

Fonte: Souza, Suertegaray e Lima (2011). 
Tomando como referência o mapa apresentado e o conhecimento de campo, os autores em destaque relatam que as áreas consideradas em processo de Desertificação Grave e Muito Grave estavam localizadas espacialmente ao longo dos rios, ocupando principalmente os vales e adjacências das bacias hidrográficas que atravessam a região, particularmente dos rios Paraíba e Taperoá, onde teríamos uso agropecuário mais intenso. Com o maior distanciamento dos cursos d'água, pelo fato de ocorrer diminuição da intensificação do uso das terras, o processo de desertificação é mapeado como Moderado.

Em condições de altitude mais elevada, associadas à presença de cursos fluviais intermitentes de tamanho reduzido e com várzeas pouco expressivas, apresenta-se uma cobertura vegetal mais preservada, onde teríamos as áreas Não Desertificadas. Correspondem, assim, às localidades menos utilizadas pelas atividades humanas em virtude da ocorrência de situações de relevo e hidrologia que dificultam o aproveitamento dessas terras.

Do ponto de vista quantitativo, excetuando-se uma pequena parcela da região que não pôde ser analisada em função da elevada cobertura de nuvens, o que comprometeu a identificação da situação dessas áreas nas imagens de satélite, Souza, Suertegaray e Lima (2011) obtiveram os resultados expressos no Quadro 1, a seguir.

\begin{tabular}{|c|c|}
\hline CLASSES TEMÁTICAS & ÁREA OCUPADA $\left(\mathbf{k m}^{\mathbf{2} / \%)}\right.$ \\
\hline Não Desertificada & $2.344,9 / 21,6$ \\
\hline Desertificação Moderada & $2.975,4 / 27,4$ \\
\hline Desertificação Grave & $2.697,1 / 24,8$ \\
\hline Desertificação Muito Grave & $2.736,7 / 25,2$ \\
\hline
\end{tabular}

Quadro 1: Área ocupada pelos diferentes níveis de desertificação no Cariri, em agosto de 2005/julho de 2006.

Fonte: Adaptado de Souza, Suertegaray e Lima (2011).

Somando-se todos os níveis de desertificação encontrados por esses autores, teríamos $8.409,2 \mathrm{~km}^{2}$ ou $77,4 \%$ da região comprometida com esse tipo de degradação, dos quais $5.433,8 \mathrm{~km}^{2}$ ou $50,0 \%$ de todas as terras analisadas classificam-se sob os níveis de desertificação Grave e Muito Grave, onde a vegetação apresentava-se com elevada escassez ou mesmo se encontrava ausente.

Em função do que foi exposto anteriormente quanto às paisagens dominantes no Cariri, temos a substituição de um bioma originalmente em grande parte florestal, onde ocorrem principalmente diversas espécies arbóreas e, secundariamente, algumas arbustivas, por uma fisionomia de savana aberta de origem antrópica, inclusive com ocorrência de poucas espécies arbustivas, como pode ser observado na Figura 3, a seguir. 


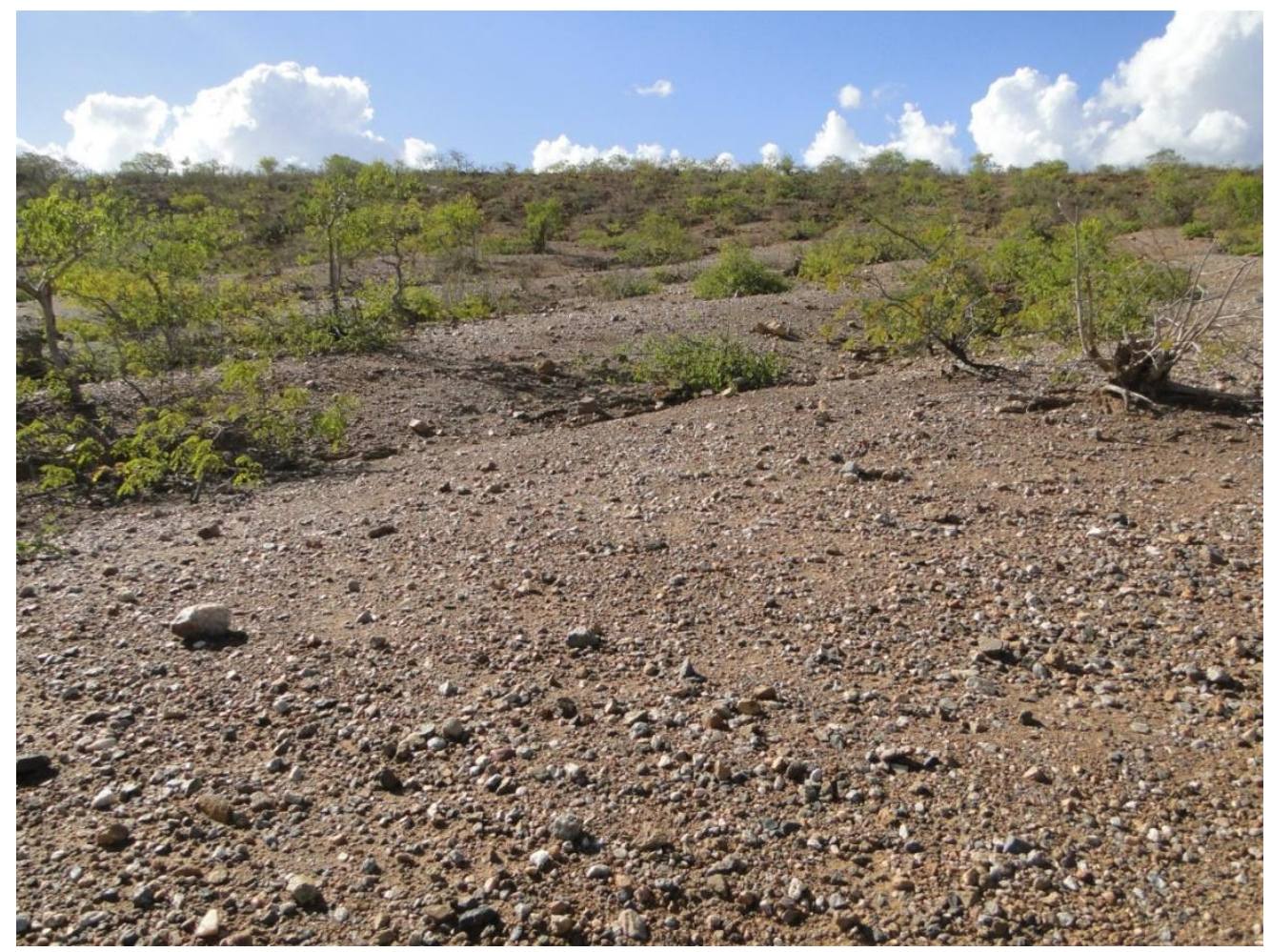

Figura 3: Caatinga arbustiva no Cariri.

Fotografia: Bartolomeu Israel de Souza, março de 2012.

Para ser realizada uma análise evolutiva da desertificação nos Cariris Velhos, Souza, Suertegaray e Lima (2011) mapearam a ocorrência do processo para o final da década de 1980, chegando ao resultado expresso na Figura 4. 


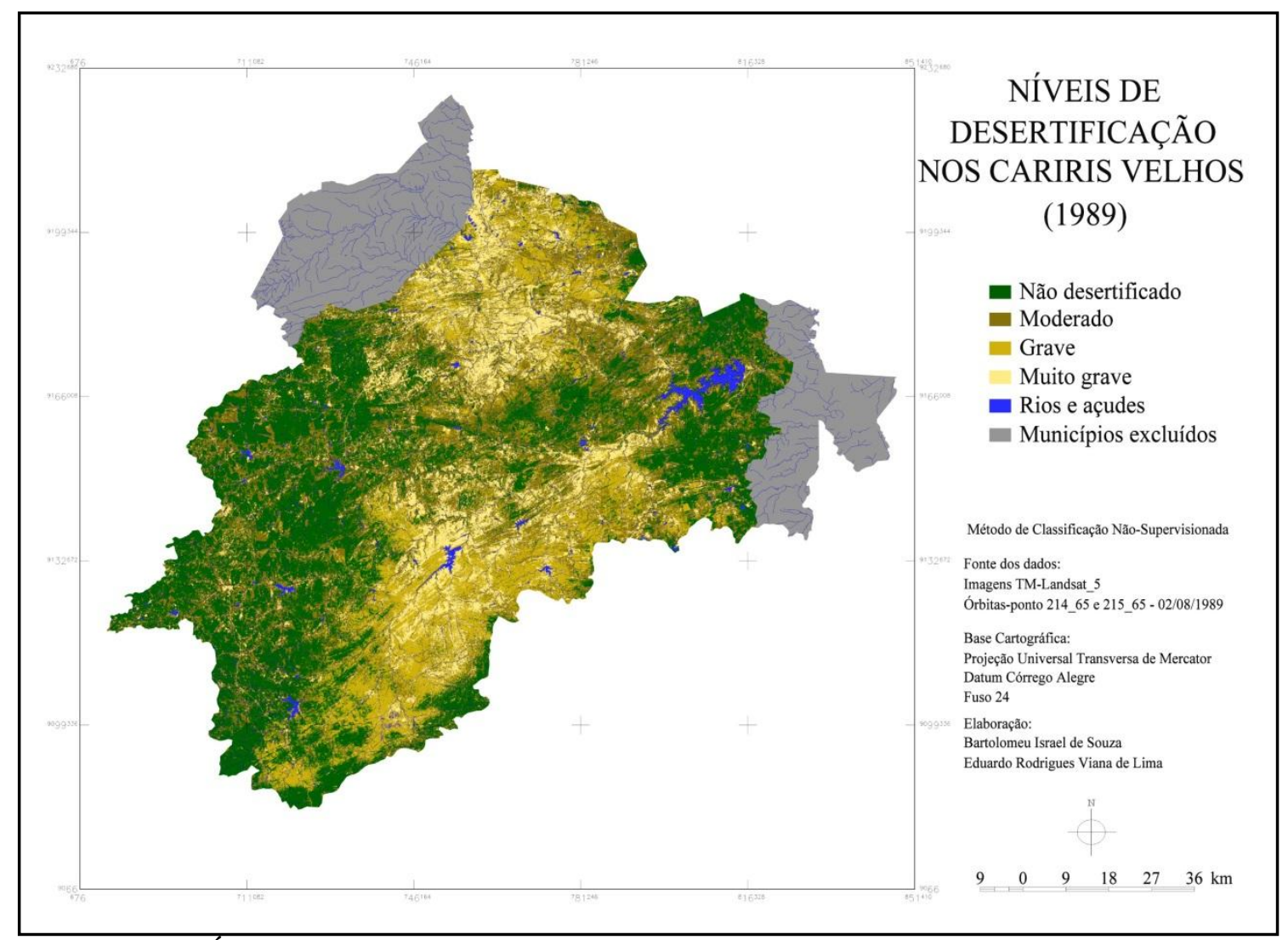

Figura 4: Áreas desertificadas no Cariri em 1989.

Fonte: Souza, Suertegaray e Lima (2011).

Tal como ocorreu na análise das imagens de satélite de 2005/2006, para o ano de 1989, os autores em destaque excluíram alguns municípios da região, uma vez que os seus territórios também estavam em grande parte encobertos por nuvens que comprometiam a visualização e quantificação da desertificação.

A análise visual da Figura 4 demonstra que em 1989, da mesma maneira que em 2005/2006, as áreas desertificadas correspondiam, principalmente, às terras mais próximas das várzeas dos rios de maior expressão na região, fato que nos remete ao processo histórico de ocupação e povoamento do Cariri, sendo esses rios mais expressivos nessas áreas - o que acarretou um consumo mais intenso das caatingas, fazendo com que em várias das terras existentes o processo de recolonização desenvolvido pela vegetação devido ao uso contínuo se torne difícil (SOUZA, SUERTEGARAY \& LIMA, 2011).

Sobre as áreas classificadas como Não Desertificadas, embora em 1989 elas apresentassem nitidamente uma área maior que em 2005/2006, sua localização 
obedeceu aos mesmos condicionantes, ou seja, regiões de mais difícil acesso à população devido aos aspectos geomorfológicos dominantes e pouca expressão dos cursos d'água em função do seu tamanho reduzido, o que favorecia o menor uso dessas terras e, consequentemente, tornou possível a presença de uma vegetação de maior porte e adensamento (SOUZA, SUERTEGARAY \& LIMA, 2011).

Comparando os dois períodos analisados, excluindo desses os municípios comprometidos por nuvens, Souza, Suertegaray e Lima (2011) chegaram aos resultados expressos no Quadro 2:

\begin{tabular}{|c|c|c|c|c|}
\hline \multirow{2}{*}{$\begin{array}{c}\text { CLASSES } \\
\text { TEMÁTICAS }\end{array}$} & \multicolumn{2}{|c|}{ ÁREA OCUPADA $\left(\mathbf{k m}^{2 / \%)}\right.$} & \multicolumn{2}{c|}{ EVOLUÇÃO } \\
\cline { 2 - 5 } & $\mathbf{1 9 8 9}$ & $\mathbf{2 0 0 5 / 2 0 0 6}$ & $\mathbf{k m}^{\mathbf{2}}$ & $\mathbf{\%}$ \\
\hline Não Desertificada & $3.225,0 / 34,4$ & $1.940,2 / 20,7$ & $-1.284,8$ & $-13,7$ \\
\hline Desertificação Moderada & $2.960,2 / 31,6$ & $2.707,6 / 28,9$ & $-252,5$ & $-2,7$ \\
\hline Desertificação Grave & $1.506,3 / 16,1$ & $2.402,0 / 25,6$ & $+895,7$ & $+9,5$ \\
\hline $\begin{array}{c}\text { Desertificação Muito } \\
\text { Grave }\end{array}$ & $1.514,5 / 16,1$ & $2.244,6 / 23,9$ & $+730,1$ & $+7,8$ \\
\hline
\end{tabular}

Quadro 2: Evolução dos níveis gerais de desertificação entre 1989 e 2005/2006 no Cariri.

Os resultados demonstraram que, em todo o período analisado, houve diminuição das áreas Não Desertificadas e com Desertificação Moderada, enquanto as áreas com Desertificação Grave e Muito Grave se expandiram. Logo, as áreas consideradas desertificadas nos seus níveis mais elevados (Grave e Muito Grave) acabaram incorporando terras anteriormente classificadas como Não Desertificadas e/ou que apresentavam Desertificação Moderada. Nesse caso, somando-se todos os níveis de desertificação encontramos para 1989 uma área degradada correspondente a 5.981,0 $\mathrm{km}^{2}(63,8 \%$ do Cariri), enquanto para 2005/2006 essas áreas corresponderam a 7.354,2 $\mathrm{km}^{2}(78,4 \%$ do Cariri). Dessa forma, nos dezessete anos observados houve um aumento de $1.373,2 \mathrm{~km}^{2}(14,6 \%)$ de áreas desertificadas no Cariri.

O quadro descrito anteriormente apresenta uma forte tendência a ser agravado, englobando cada vez mais as poucas áreas que apresentam algum tipo de vegetação melhor preservado, incluindo-se nelas as duas únicas Unidades de Conservação existentes na região, que, além de representarem muito pouco das terras do Cariri, ainda que sejam classificadas como de uso sustentável, efetivamente não fazem jus a essa denominação, já que em geral o uso dos recursos naturais aí existentes ocorre de forma praticamente tão degradadora como nas áreas de entorno (PARAÍBA, 2011). 
Entendendo a desertificação nessa região como uma consequência das formas de ocupação e uso das terras que vêm procedendo historicamente, cabe analisar como ocorreram estes processos nos quais, em princípio, a água, quer seja pela presença ou ausência, caracterizou-se como um dos principais definidores do modelo de organização do espaço em questão.

\section{Uso e manejo tradicional dos solos}

No Cariri paraibano, conforme destacado anteriormente, muitas particularidades em relação aos diversos tipos de usos dos recursos naturais estão diretamente relacionadas às condições hídricas. Por exemplo, em relação à pecuária, ao contrário do restante do semiárido, onde geralmente domina o criatório bovino, nessas terras a caprinocultura extensiva sempre se constituiu historicamente como a atividade mais tradicional, uma vez que está mais adaptada às condições ecológicas dominantes, em que temos carência pluviométrica máxima. Quanto à agricultura, por sua vez, enquanto nos "outros Sertões", nas grandes várzeas, é comum o plantio do arroz-daterra e da macaxeira para subsistência e, ocasionalmente, para o mercado, a menor disponibilidade hídrica dominante no Cariri torna o cultivo desses gêneros alimentícios mais difícil, ocorrendo com menor frequência.

Do ponto de vista da repartição do uso, mais evidente que em outras regiões do Sertão nordestino, as terras do Cariri são tradicionalmente ocupadas pensando no quanto de água necessita a atividade desenvolvida, o que faz com que a criação de caprinos se concentre nas áreas de vertentes, onde geralmente dominam solos do tipo Luvissolo Crômico e menor potencial hídrico, alimentando-se da vegetação nativa ao longo de todo o ano; enquanto nas várzeas dos rios temporários, onde temos a presença dos solos do tipo Neossolo Flúvico e maior umidade, são cultivados diversos produtos agrícolas. Nessas últimas áreas também ocorre um pouco de pecuária em alguns setores, notadamente bovinos e ovinos, pelo fato desses serem mais exigentes em relação a alimentos e água que os caprinos.

A descrição desse quadro pode ser observada no esquema representativo dessa realidade nos dias atuais, apresentada na Figura 6, a seguir. 


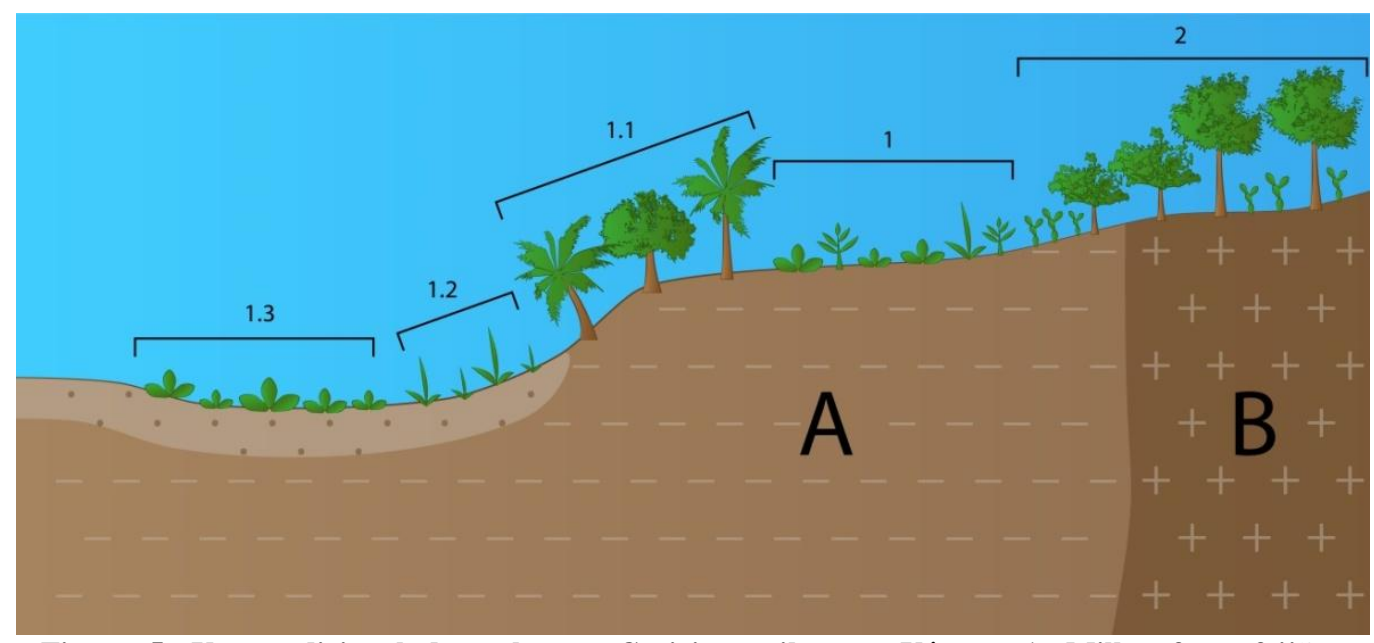

Figura 5: Uso tradicional dos solos no Cariri paraibano - Várzea: 1- Milho, fava, feijãomacassar, abóbora e melancia; 1.1- Mangueira, coqueiro, goiabeira e cajueiro, mamão e bananeira; 1.2- Capim-elefante; 1.3- Batata-doce e feijão-macassar; Limite Várzea/Vertente: 2Algaroba, palma-forrageira e capim-buffel.

Observação: A - Neossolo Flúvico; B- Luvissolo Crômico.

Idealização: Bartolomeu Israel de Souza.

Desenho: Rafael Luna de Menezes.

Destacamos, ainda, que quando dizemos que a ocupação dessas áreas fica na dependência direta das condições hídricas dominantes, isso também ocorre nas menores porções das propriedades. Portanto, a organização e repartição das culturas refletem um elevado conhecimento das relações existentes entre a chuva em seu período de ocorrência e distribuição, os tipos de solos em sua fertilidade e capacidade de armazenar mais ou menos água, a condição de relevo, entre outros detalhes, o que reflete muito do empirismo e do conhecimento ancestral quanto à percepção das pequenas diferenças entre as distintas partes das várzeas e das vertentes.

Em função do exposto, nas áreas de várzea a limpeza dos solos (retirada e queima da cobertura vegetal, denominada em todo o semiárido brasileiro de broca e coivara) começa no mês de novembro, no qual temos, em geral, o final da estação seca. Daí em diante, é seguida uma dinâmica em relação ao que será plantado e em que parte da várzea isso ocorrerá, obedecendo ao ritmo das chuvas e da seca e os seus efeitos nessa parte do vale quanto a maior ou menor presença de umidade. Tendo por base a distribuição dos diferentes usos dos solos nas áreas de várzea, observados na Figura 5 , teremos os seguintes produtos agrícolas, em que são utilizadas técnicas simples e eficientes:

- Milho e fava: Plantados na mesma cova. Se as chuvas forem mais frequentes, a semeadura é iniciada em fevereiro. A colheita dos dois cultivos ocorre em três 
meses, enquanto a fava é colhida em setembro, quando está seca. Com a retirada da espiga, o restante do corpo do milho serve de suporte para a fava enramar;.

- Feijão-macassar: Plantado no mês de fevereiro, em cova própria, ao lado do milho e da fava, enramando no solo. Sua colheita é feita no mesmo período que o milho (três meses após a semeadura).

- Abóbora e melancia: Plantados no mesmo período do milho, da fava e do feijãomacassar, em covas distintas para aproveitar melhor a luz e evitar competição por nutrientes. Para tanto, as covas se distanciam em cerca de 2 metros umas das outras, permitindo que esses cultivos ocupem o solo do entorno com galhos e folhas enramados.

- Capim-elefante: Principal gramínea cultivada nas várzeas dos rios, devido à sua elevada necessidade de umidade. Apesar de muitas vezes ser cultivada anualmente, vem apresentando ocorrência espontânea na região.

- Árvores frutíferas: Mangueira, coqueiro, goiabeira e cajueiro são plantados no leito maior dos rios, atingidos com pouca frequência pelas inundações anuais, enquanto o mamão e a bananeira são cultivados no leito menor, por serem mais exigentes em termos de umidade que as primeiras espécies citadas.

- Batata-doce e feijão-macassar: Plantados em junho, quando o leito do rio está seco. No caso do feijão-macassar, corresponde à segunda semeadura do ano deste produto, sendo a colheita de ambos ocorrendo três meses após o plantio.

A adubação artificial para o desenvolvimento dessas culturas nessas áreas é praticamente inexistente. Ainda assim, como os solos têm a sua fertilidade renovada a cada período de enchente, na estação chuvosa, seguido de um longo período de seca no qual essas terras ficam em grande parte isentas de um uso mais intenso, essa dinâmica preserva tal parte das propriedades de grandes efeitos degradadores.

No limite das várzeas com as vertentes, ocupando mais o segundo compartimento de relevo que o primeiro, tal como exposto na Figura 5, temos:

- Algaroba, palma-forrageira e capim-buffel: Plantados nessa área por serem menos exigentes em termos de água que os produtos agrícolas cultivados. A algaroba é uma espécie arbórea exótica, originária do Peru introduzida na década de 1940 no semiárido brasileiro para servir de alimento ao gado (DRUMONDET et al., 2010), apresentando colonização espontânea devido principalmente à dispersão das suas sementes pelo gado.

A palma-forrageira é uma cactácea exótica originária do México, também utilizada como espécie forrageira. Sua introdução é bastante antiga, ocorrendo desde o final do século XVIII inicialmente para a produção do corante vermelho conhecido como carmim, a partir do parasitismo exercido na espécie pelo inseto cochonilha. Com o tempo, passou a ser utilizado como alimento para o gado (SIMÕES, SANTOS \& DIAS, 2005), muitas vezes sendo plantada em consórcio com o algodão, embora desde o final dos anos 1980 isso quase não ocorra 
mais, em função da crise que desestimulou o cultivo dessa fibra na região. O plantio de novas mudas é iniciado em fevereiro, com a chegada das primeiras chuvas.

Quanto ao capim-buffel, trata-se de uma gramínea exótica originária da África introduzida no século XX com grande adaptação ao clima semiárido. Em função do custo das sementes, é mais comum a sua presença em propriedades cujos donos possuem maior poder aquisitivo.

Depois de efetuada a colheita, os restos de galhos e folhas dos gêneros alimentícios (denominados regionalmente de restolho) são aproveitados no restante do ano como alimento para o gado bovino e ovino, em pastagem direta nas várzeas ou fornecidos aos animais nos currais. Essa alimentação é complementada na estação seca pelo consumo de milho, vagens de algaroba e palma-forrageira, sendo estas, vez ou outra, também fornecidas aos caprinos, os quais ocupam praticamente $\mathrm{o}$ ano inteiro as áreas de vertentes, consumindo o pasto nativo.

Ainda sobre a algaroba, suas vagens e, ocasionalmente, as folhas são cedidas ao gado no curral, ainda que também seja comum o seu consumo diretamente nas pastagens, onde muitas vezes é plantada em consórcio com o capim-buffel. Sobre a palma-forrageira, o seu consumo se dá quando os produtores cortam algumas partes para serem consumidas no curral. Em anos de secas prolongadas, essa planta é uma das poucas à qual os produtores podem recorrer para alimentar o gado, inclusive pelo fato de muitas espécies da caatinga utilizadas no passado para esses períodos de falta de chuva terem suas populações reduzidas de forma intensa, a exemplo de diversas cactáceas e bromeliáceas.

Destaca-se que nesse sistema o conhecimento do produtor sobre a diversidade florística e o seu aproveitamento diferenciado como alimento pelos tipos de gado também funcionava em um passado recente como um trunfo para a sobrevivência do rebanho. Por exemplo, embora o marmeleiro (Croton sonderianus) seja uma espécie arbustiva bastante abundante nos pastos nativos, como as suas folhas são tóxicas quando verdes o seu consumo pelo gado só se dava no final da estiagem após a sua queda, aproveitando-as principalmente para os caprinos.

Ainda nesse sistema, os bovinos se alimentavam preferencialmente das gramíneas nativas e, à medida que essas iam escasseando, complementavam a sua dieta com as folhas de algumas árvores, especialmente de Leguminosas como a catingueira (Poincianella pyramidalis) e a jurema-branca (Mimosa ophthalmocentra). Esse conhecimento permitia que os produtores, nos anos de chuvas mais regulares, deixassem o rebanho ou parte dele até seis meses nos pastos nativos (COHEN E DUQUÉ, 2001), ao passo que no restante do ano era oferecida aos animais a biomassa contida nas zonas agrícolas, através do aproveitamento do restolho.

Mesmo que em alguns períodos a ocorrência de secas mais acentuadas pudesse afetar a estabilidade desse sistema, podemos dizer que no geral o aproveitamento racional dos solos se manteve durante vários anos em virtude da abundância de terras a serem utilizadas, existindo um período de pousio para as parcelas utilizadas que garantia uma produtividade capaz de satisfazer as necessidades dos 
agricultores/criadores em relação à sua subsistência e/ou a produção para o mercado. Entretanto, analisada em uma perspectiva temporal mais contemporânea na história do Cariri, esse modelo, à exceção de algumas poucas propriedades, tem sido gradativamente modificado, o que vem acarretando uma séria crise, tanto do ponto de vista econômico como ambiental.

\section{Dinâmica recente do uso dos solos e da agropecuária nos Cariris Velhos}

Séculos de repartições das propriedades por herança entre os familiares e a criação mais recente de diversos assentamentos de terra pelo governo brasileiro em todo o semiárido fizeram com que a pressão sobre este meio fosse ficando cada vez mais elevada (SIMÕES, SANTOS \& DIAS, 2005), já que passou a ocorrer a diminuição do tempo de descanso (pousio) das terras entre as colheitas, o que acarretou uma maior intensificação do uso dos solos e da vegetação nativa, gerando a desertificação em várias áreas. Além disso, o grande número de pequenas propriedades resultante desse processo também tornou mais difícil, pela exiguidade de terras disponíveis, a aplicação de alguns conhecimentos tradicionais de convivência com o semiárido, como o manejo do gado nos pastos nativos.

Em função do exposto, muitos agricultores foram obrigados a intensificar o uso dos solos e da vegetação nativa, no Cariri e em outras regiões do semiárido, não tendo havido, na mesma proporção, ajustes na base tecnológica, o que a fez permanecer dominada por métodos extensivos de uso e manejo ambiental (SIDERSKY \& SILVEIRA, 1998), gerando incompatibilidade entre a intensidade de exploração dos recursos naturais e a capacidade de regeneração dos ecossistemas, comprometendo a sustentabilidade dos agroecossistemas tradicionais. Ao mesmo tempo, num processo de retroalimentação, particularmente o setor agrícola familiar com poucos recursos monetários se vê cada vez mais fragilizado (PETERSEN, SILVEIRA \& ALMEIDA, 2002).

Da mesma forma, acrescentamos que a intensificação de políticas públicas efetuadas pelo governo federal voltadas ao incentivo à pecuária nessa região tem afetado diretamente e cada vez mais o sucesso desse modelo tradicional de uso das terras, conforme destacado em Souza, Suertegaray e Lima (2010).

Dentre as políticas públicas desenvolvidas no Cariri, ressaltamos o apoio à pecuária e, no seio desta, particularmente a caprinocultura que, sendo tradicional na região devido à grande adaptação desse tipo de gado às condições de escassez de água e alimento dominantes, passou a receber atenção especial desde a década de 1970 por meio de incentivos governamentais com o objetivo de aumentar o número de cabeças, melhorar o padrão genético e alavancar o aproveitamento dos produtos derivados, tentando modernizar a produção para fins mais comerciais, o que faz com que essa atividade seja atualmente dominante (SOUZA, SUERTEGARAY E LIMA, 2010). 
O Quadro 3, a seguir, demonstra o grande crescimento recente dessa atividade e particularmente do rebanho em destaque nessa região, o qual chega em diversos momentos a ter praticamente o somatório do número de cabeças de bovinos e ovinos, até mesmo superando o número destes em alguns dos anos expostos.

\begin{tabular}{|c|c|c|c|}
\hline \multirow{2}{*}{ ANOS } & \multicolumn{3}{|c|}{ REBANHO } \\
\cline { 2 - 4 } & Bovinos & Ovinos & Caprinos \\
\hline 2006 & 123.803 & 134.577 & 304.105 \\
\hline 2007 & 127.213 & 138.066 & 309.136 \\
\hline 2008 & 130.625 & 140.825 & 316.007 \\
\hline 2009 & 134.742 & 145.996 & 317.066 \\
\hline 2010 & 138.989 & 147.502 & 298.363 \\
\hline 2011 & 151.901 & 154.813 & 278.060 \\
\hline 2012 & 101.664 & 128.543 & 227.221 \\
\hline
\end{tabular}

Quadro 3: Evolução recente da pecuária no Cariri (número de cabeças).

Fonte: IBGE - Pesquisa Agropecuária Municipal/PB (2006 a 2012).

Paralelo ao crescimento desse rebanho e da diminuição do tamanho das propriedades, ocorre importante contribuição dessa atividade ao processo de desertificação que já vinha acontecendo no Cariri. Neste caso, os hábitos alimentares desses animais e principalmente a forma semiextensiva como os mesmos continuam a ser criados fazem com que estes permaneçam, na maioria das propriedades do Cariri, totalmente dependentes da alimentação disponível na vegetação nativa de caatinga. Isso, associado às transformações na estrutura fundiária, torna a herbivoria uma característica comum nessas terras (SOUZA, SUERTEGARAY E LIMA, 2010).

Ao analisar essa questão de forma geral, leva-se em consideração que para viabilizar a reprodução e acumulação dos meios de produção de uma família nas áreas mais secas do semiárido nordestino são necessários ao menos de 200 a 300 hectares para manter em condições tradicionais (semiextensiva) um rebanho de cabras para corte com 300 matrizes. Sabendo que cerca de três quartos das propriedades nessa região não atingem esse tamanho, inclusive no Cariri, conforme os dados de Souza, Suertegaray e Lima (2010), as condições de pouco capital, carência de água e de recursos vegetais tornam essa atividade econômica altamente degradadora (GUIMARÃES FILHO \& LOPES, 2001), ficando também seriamente comprometida a sua continuidade do ponto de vista econômico, ainda que essas consequências chamem mais atenção na estação seca.

Durante essa estação temos uma queda acentuada da biomassa e consequentemente menor oferta de alimento para o gado, passando a existir um impacto que também atinge os caprinos, relacionado à diminuição na produção de leite e carne. Quando a estiagem é mais prolongada que o normal, temos a morte parcial do rebanho por falta de alimento disponível nas pastagens nativas, já que 
antes da seca uma grande variedade de espécies da caatinga já estava comprometida pelo uso excessivo por parte desses animais e também pela retirada da madeira para construção de cercas, produção de lenha e carvão vegetal para uso doméstico e industrial (SOUZA, SUERTEGARAY \& LIMA, 2011).

Essa situação, longe de ser uma especificidade do semiárido brasileiro, é muito comum em outras regiões de clima seco do mundo. Neste sentido, Hare et al. (1992) destacam que no Sahel (África) a morte do gado na grande estiagem ocorrida na década de 1970 se deu muito mais pela falta de alimento disponível que pela carência de água. Sendo assim, a atividade criatória, ao fazer o uso excessivo da vegetação em algumas áreas submetidas à carência hídrica, ao mesmo tempo em que cria parte do problema da desertificação, também sofre as suas consequências, sendo uma questão de ampla abrangência geográfica no mundo e de verificação histórica de longa data.

No caso do semiárido da Paraíba, ainda que intensificado mais recentemente, esse problema é bastante antigo, como alguns autores deixaram registrado em importantes documentos.

No contexto anterior, destacamos as observações de Joffily (1892), o qual menciona a inexistência de preocupação por parte dos produtores em relação à capacidade de carga que poderia suportar a vegetação das caatingas submetida à pecuária com a sua consequente degradação, o que pode ser tido como a primeira observação dos efeitos da desertificação provocados pelo pastoreio na história dessa parte do Brasil. Essa questão é destacada por Almeida (1994) no início do século $\mathrm{XX}$, ao observar que a multiplicação dos rebanhos nas áreas mais secas do estado contribuía decisivamente para os impactos na vegetação, degenerando o gado em momentos de intervalos mais largos entre as estiagens, quando os proprietários multiplicavam os seus rebanhos.

Direcionando suas observações ao Cariri, Almeida (1994) denomina essas terras de "paraíso das cabras", enfatizando o papel desses animais como criadores de desertos devido às suas características alimentares, o que se torna de fácil entendimento quando se sabe que, ainda que prefiram o consumo de plantas arbustivas e arbóreas, também são grandes consumidores de espécies herbáceas (SOARES, GUIMARÃES FILHO \& SALVIANO, 2006), chegando a se alimentar de até $70 \%$ das espécies existentes nas caatingas (ARAÚJO FILHO, BARBOSA \& CARVALHO, 1999).

Portanto, um número expressivo desses animais em determinadas áreas, dependendo da quantidade da vegetação nativa disponível para consumo, acarreta sérios problemas de degradação, particularmente quando essas características estão associadas à ocorrência de secas de longa duração (ALBUQUERQUE et al., 2004), uma vez que isso implica menor oferta de alimentos para os caprinos.

Sobre a presença de uma estação seca dominante, esta é uma característica inerente à semiaridez. No caso do Sertão nordestino, seu prolongamento está associado à atuação do fenômeno El Niño. Entre 1950 e 2004, o Centro de Previsão 
de Tempo e Estudos Climáticos (CPTEC), órgão ligado ao Instituto Nacional de Pesquisas Espaciais (INPE), registrou 18 ocorrências dessa anomalia climática, sendo as mais intensas as de 1982-1983 e 1997-1998 (SOUSA, 2007), às quais podemos juntar, com duração prolongada no Cariri, a presença mais recente dessa anomalia entre os anos 2011 a 2016.

Associando a ocorrência do El Niño à variabilidade espacial das chuvas (mesmo em anos considerados de pluviosidade média normal) e a já pequena pluviosidade média dominante no Cariri (cerca de $500 \mathrm{~mm} / \mathrm{ano}$ ), a presença e ausência de pastagem nessa região acabam se tornando tão desuniformes territorialmente quanto à própria pluviosidade. Nesse sentido, relacionando secas prolongadas, rarefação da vegetação e herbivoria, acabamos tendo uma forte ocorrência de degradação das caatingas e, consequentemente, desertificação.

Ainda em relação aos hábitos alimentares e a herbivoria provocada pelos caprinos em áreas de caatinga, um importante trabalho foi desenvolvido por Leal, Vicente e Tabarelli (2005) na região de Xingó, estado de Alagoas. Tal pesquisa constatou que esses animais constituem importante fator de seleção natural, afetando principalmente arbustos e árvores perenifólias, como o juazeiro (Ziziphus joazeiro) e o umbuzeiro (Spondias tuberosa), ou espécies decíduas com ciclo reprodutivo parcial ou completo na estação seca, como a aroeira (Myracroduon urundeuva) e a imburana (Commiphora leptophoeos).

Todas as espécies mencionadas são clímax na caatinga. A diminuição dos seus números mediante a ação dos caprinos ocorre em função de estarem acessíveis ao pastoreio na época em que estes animais dependem exclusivamente da vegetação lenhosa para se alimentarem. Além disso, no consumo de alguns frutos nativos, algumas sementes são totalmente trituradas, impedindo-se assim a sua reprodução.

Dessa forma, esse estudo indica que altas taxas de lotação de caprinos em áreas de caatinga, quando associadas a outras formas de pressão sobre a vegetação e secas prolongadas, têm o poder de empobrecer e reduzir o porte das plantas, levando à ocorrência de desertificação, o que também já foi constatado em outras regiões semiáridas fora do Brasil (LEAL, VICENTE \& TABARELLI, 2005).

Esta pressão dos caprinos sobre a vegetação nativa tem sido ainda mais acentuada recentemente, em função do cultivo de produtos agrícolas utilizados na complementação alimentar do gado estarem, no geral, diminuindo, tanto em área ocupada como em produção, conforme pode ser visto no Quadro 4, abaixo. 


\begin{tabular}{|c|c|c|c|c|}
\hline \multirow{2}{*}{ ANOS } & \multicolumn{2}{|c|}{ LAVOURA PERMANENTE } & \multicolumn{2}{c|}{ LAVOURA TEMPORÁRIA } \\
\cline { 2 - 5 } & Hectares & Toneladas & Hectares & Toneladas \\
\hline 2006 & 70 & 52 & 53.434 & 27.192 \\
\hline 2007 & 11 & 9 & 27.218 & 11.526 \\
\hline 2008 & 18 & 14 & 56.942 & 26.042 \\
\hline 2009 & 65 & 56 & 57.524 & 22.376 \\
\hline 2010 & 19 & 18 & 20.795 & 5.661 \\
\hline 2011 & 15 & 17 & 46.116 & 13.417 \\
\hline 2012 & 26 & 26 & 2.768 & 1.204 \\
\hline
\end{tabular}

\section{Quadro 4: Evolução recente da agricultura no Cariri.}

Fonte: IBGE - Produção Agropecuária Municipal/PB (2006 a 2012).

Obs: : Lavoura Permanente = Algodão arbóreo; Lavoura Temporária = Algodão herbáceo, feijãomacassar, milho, fava, melancia e batata-doce.

Essa mesma situação vem ocorrendo com o cultivo da palma-forrageira, cuja área ocupada e produção seguem uma tendência de severa diminuição na região (SOUZA, SUERTEGARAY E LIMA, 2010). Além disso, sabe-se que a espécie tem sido muito afetada pela praga do inseto cochonilha, o que tem feito com que as plantações dessa cactácea estejam drasticamente afetadas e, em muitos casos, até mesmo extintas em algumas áreas do Cariri.

Em função do exposto, ainda que percebamos a importância da influência das secas na região enquanto fenômenos capazes de afetar a produção agropecuária, entendemos que mais importante que este fenômeno natural são as intervenções de programas governamentais que não têm dado atenção suficiente às características naturais da região, às ligações entre o aumento da pecuária e a oferta de alimento para o gado, associando essas questões aos impactos ambientais já existentes e aos que poderão ocorrer ou serem agravados.

As consequências destacadas, para além dos aspectos econômicas e ambientais, vão ainda mais longe, afetando também a cidadania de grande parte da população do Cariri. Entretanto, antes dessa discussão, é preciso destacar que a fome pela qual passava grande parte dos habitantes dessa região nas épocas de secas mais acentuadas não é mais dominante nessa parte do país como ocorria em um passado recente, devido a atuação de diversos programas do Governo Federal, resolvendo quase por completo esse problema ao expandir o número de pessoas beneficiadas pelas aposentadorias e por diversos programas assistencialistas de ajuda financeira 
às famílias carentes, dentre os quais destacamos o Bolsa Família. Conforme dados do Ministério da Previdência Social - MPS (MPS, 2010) e do Instituto de Pesquisas Econômicas Aplicadas - IPEA (IPEA, 2010), para o ano 2010 o número total de beneficiados por esses programas governamentais em todo o Cariri paraibano foi de 63.228 pessoas, o que correspondia a $34,3 \%$ da população existente nesse ano (185.235 habitantes), enquanto em termos municipais esse número de dependentes variava no mínimo em $12,3 \%$ e no máximo em $50,5 \%$.

Pelo exposto acima, esses programas representam uma injeção de capital de fundamental importância para movimentar a economia dessas terras, ainda que a produção agropecuária não seja das mais expressivas, caracterizando fielmente o que Gomes (2001) denomina de "economia sem produção". Isso repercute diretamente na melhoria da qualidade de vida da população, como pode ser visto nos dados recentes do Índice de Desenvolvimento Humano - IDH para o Cariri (PARAÍBA, 2011).

Por um lado, se entendemos que esses programas têm gerado diversos benefícios sociais e econômicos indiretos inegáveis, percebemos também um forte impacto negativo no que diz respeito à condição de cidadania, no sentido pleno da palavra, dos habitantes dessa parte do Nordeste do Brasil, já que as ações dominantes não são acompanhadas há décadas e na mesma proporção de um projeto de geração de trabalho e renda sustentáveis na região. Portanto, cada vez mais pessoas se tornam não apenas dependentes, mas também reféns dessas políticas públicas, para atender inclusive às suas necessidades mais básicas de sobrevivência nessas terras, sujeitas a secas severas e com pouco capital produtivo. Dessa forma, muito semelhante à época de domínio de algumas oligarquias familiares na região, perpetua-se com outro formato um modelo tradicional de aliciamento (ainda que sutil) por parte de quem está no poder, exercendo uma influência decisiva quanto às decisões e opções políticas que devem ser tomadas pela maioria das pessoas, estabelecendo-se uma situação que, senão impossível, é de difícil solução em curto prazo.

As questões anteriormente levantadas puderam ser vistas mais uma vez, de forma mais explícita, na forte estiagem ocorrida a partir de 2011 e que se estende até o presente momento no Cariri e em todo o semiárido brasileiro, quando estamos tendo inúmeras consequências na economia e em uma série de elementos constituintes de uma natureza, como diz Suertegaray (2001), transfigurada.

Indo além, se analisadas na perspectiva das intervenções governamentais criadas para solucionar a questão da desertificação e dos efeitos negativos das secas no semiárido brasileiro, observamos que em muitos pontos as ações pensadas e já praticadas para resolver esses problemas têm uma incompatibilidade quase total.

No contexto anteriormente descrito, doze anos após a criação do Programa de Ação Nacional de Combate à Desertificação e Mitigação dos Efeitos da Seca PAN/Brasil (BRASIL, 2004) e cinco anos após a criação do Plano de Ação Estadual de Combate à Desertificação e Mitigação dos Efeitos da Seca - PAE/PB (PARAÍBA, 2011), a articulação prevista entre as diversas políticas nacionais que 
buscam viabilizar a implementação de modelos de desenvolvimento sustentável estão muito aquém do prometido na maioria dos quatro eixos temáticos previstos: 1 - Redução da pobreza e da desigualdade; 2 - Ampliação sustentável da capacidade produtiva; 3 - Conservação, preservação e manejo sustentável dos recursos naturais; e 4 - Gestão democrática e fortalecimento institucional.

Para longe de serem analisados isoladamente em suas causas e consequências, esses eixos devem, obrigatoriamente, ser vistos em suas relações. Nesse caso, sobre o eixo 1, reconhecemos que os objetivos propostos têm sido atingidos aos poucos, ainda que seja, conforme já destacamos, às custas de uma verdadeira cidadania política. Nesse caso, se torna difícil a prática real da gestão democrática, como previsto no eixo 4 dos documentos em questão.

Em se tratando dos eixos 2 e 3, conforme pudemos observar para o Cariri, como um termômetro do que vem ocorrendo em grande parte do restante do semiárido brasileiro, a situação atual é bastante preocupante, ao mesmo tempo em que as perspectivas para um futuro próximo também não podem ser consideradas das melhores para a região, já que não percebemos mudanças substanciais a curto e médio prazo que possam promover o prometido.

\section{Considerações Finais}

Ao analisarmos o processo de desertificação nos Cariris Velhos, consideramos que este faz parte de um processo histórico relacionado principalmente à forma como se deu o uso dos solos nessa região, sem que se tenha respeitado as especificidades e fragilidades naturais dessas terras de clima semiárido, particularmente quando foram implantadas algumas atividades econômicas mais intensivas.

Mesmo que não neguemos esse passado criador deste tipo de degradação, também observamos em paralelo à existência desse impacto ambiental a forte presença de práticas agropecuárias tradicionais que ainda hoje apresentam algumas de suas marcas nessas paisagens, as quais exerciam menor pressão ambiental, oferecendo também uma razoável segurança alimentar e hídrica, tanto para as pessoas como para o gado, devido à complementaridade existente entre as atividades agropecuárias, associada à presença de maior disponibilidade de terras para que pudessem ser exercidas várias formas de uso dos solos, ainda que esse modelo entrasse em crise nos eventos anômalos de secas mais acentuadas.

Sobre as dinâmicas recentes de usos de solos nessa região, a exemplo do que vem ocorrendo com o restante do semiárido brasileiro, defendemos que embora estas não sejam necessariamente criadoras do processo de desertificação, vêm acentuando a degradação em questão, cabendo ao Estado papel decisivo na forma como vem se processando essa dinâmica, tanto através da oferta de incentivos financeiros à intensificação da prática de certas atividades econômicas, como pelas falhas 
cometidas nesse processo, principalmente ao investir em ações intervencionistas baseadas no aumento da produção sem ter a atenção devida à capacidade dessas terras em absorver de forma sustentável a nova realidade estabelecida, o que também repercutiu para muitos proprietários de terra, tanto grandes como pequenos, seduzidos pelo sonho de melhoria econômica, reproduzindo, assim, uma lógica puramente produtivista, para a qual a caprinocultura é o destaque nos Cariris Velhos.

Ainda assim, a exemplo do que aconteceu ao fim de outros períodos com estiagens prolongadas, o que já começa a ser observado em 2016, quando as previsões meteorológicas indicam a volta das condições "normais" de chuva no semiárido brasileiro, ou até mesmo de uma pluviosidade acima da média, é a continuidade da reprodução de um ciclo vicioso, no qual os produtores já começam a esboçar a intenção de substituir os animais perdidos durante o longo período de seca, procurando recuperar o prejuízo e, se possível, aumentar ainda mais o rebanho, não se percebendo no mesmo nível de importância a manifestação explícita de uma preocupação, tanto por parte dos pecuaristas como do Estado, em criar mecanismos capazes de gerar alimento suficiente para o novo rebanho que irá se estabelecer, o que, por sua vez, passa pela discussão e prática de uma política ambiental realmente adequada para a região.

Dessa forma, o que se apresenta ao fim de mais uma grande seca nessa região é a continuidade de uma situação que vem marcando de forma intensa as paisagens do Cariri, onde temos uma vegetação cada vez menos diversificada e de pequena densidade, com presença de solos quase completamente desnudos, mesmo durante a estação chuvosa. Cabe, assim, repensar o semiárido brasileiro respeitando as suas especificidades naturais e estabelecendo formas de uso do solo menos impactantes ambientalmente, ao mesmo tempo em que as intervenções econômicas e políticas que venham a ser feitas sejam geradoras de uma verdadeira cidadania.

\section{Bibliografia}

ALBUQUERQUE, S. G.; SOARES, J. G. G.; GUIMARÃES FILHO, C.; OLIVEIRA, M. C. (2004). Dinâmica do estrato herbáceo de uma vegetação de caatinga do sertão pernambucano, sob intensidades de uso por caprinos. Petrolina: Embrapa. Disponível em:<www.cpatsa.embrapa.br>. Acessado em: 04 jan. 2013.

ALMEIDA, J. A. (1994). A Paraíba e seus problemas. 4. ed. Brasília: Senado Federal/Fundação Casa de José Américo.

ARAÚJO FILHO, J. A.; BARBOSA, T. M. L.; CARVALHO, F. C. (1999) Sistema de produção silvopastoril para o semi-árido nordestino. Sobral: Boletim da Embrapa, 29. pp. 1-2.

AUBRÉVILLE, A. (1949). Climats, Forêts et Desertification de l'Afrique tropicale. Paris: Societé d'Éditions Gégraphiques, Maritimes et Coloniales. 
BRASIL (2004). Programa de Ação Nacional de Combate à Desertificação e Mitigação dos Efeitos da Seca/PAN-Brasil. Brasília (DF): Ministério do Meio Ambiente/Secretaria de Recursos Hídricos.

CCD (1995). Convenção das Nações Unidas de Combate à Desertificação. Tradução: Delegação de Portugal. Lisboa: Instituto de Promoção Ambiental.

COHEN, M. \& DUQUÉ, G. (2001). Les deux visages du Sertão. Stratégies paysannes face aux sécheresses (Nordeste, Brésil). Paris (FR): IRD.

DRUMOND, M. A.; RIBASKI, J.; SÁ, I. B.; NASCIMENTO, C. E. S.; OLIVEIRA, V. R. (2010) Espécies arbóreas exóticas de uso múltiplo para o semiárido brasileiro. In: SÁ, I. B.; SILVA, P. C. G. (Ed.). Semiárido brasileiro. Pesquisa, desenvolvimento e inovação. Petrolina: Embrapa Semiárido. pp. 245-274.

GOMES, G. M. (2001). Velhas secas em novos sertões. Continuidade e mudanças na economia do Semiárido e dos Cerrados nordestinos. Brasília: IPEA.

GUIMARÃES FILHO, C.; LOPES, P. R. C. (2001). Subsídios para formulação de um programa de convivência com a seca no semiárido brasileiro. Petrolina: Embrapa Semiárido.

HARE, F. K.; WARREN, A.; MAIZELS, J. K.; KATES, R. W.; JOHNSON, D. L.; HARING, K. J.; GARDUÑO, M. A. (1992) Desertificação: uma visão global. In HARE, F. K.; WARREN, A.; MAIZELS, J. K.; KATES, R. W.; JOHNSON, D. L.; HARING, K. J.; GARDUÑO, M. A. (Org.). Tradução: Henrique de Barros e Ário Lobo de Azevedo. Desertificação: Causas e Consequiências. Lisboa: Fundação Galouste Gulbenkian. pp. 11-108.

INSTITUTO BRASILEIRO DE GEOGRAFIA E ESTATÍSTICA (IBGE) Pesquisa Agropecuária Municipal/PB 2006 a 2012. Disponível em: <http://www.sidra.ibge.gov.br>. Acessado em: 26 nov. 2013.

INSTITUTO DE PESQUISAS ECONÔMICAS APLICADAS (IPEA) Dados de gastos com programas sociais 2010. Disponível em: 〈http://www.ipeadata.gov.br〉. Acessado em: 30 ago. 2013.

JOFFILY, I. (1892). Notas sobre a Parahyba. Rio de Janeiro: Typographia do Jornal do Commercio.

LEAL, I. R.; VICENTE, A.; TABARELLI, M. (2005) Herbivoria por caprinos na caatinga da região de Xingó: uma análise preliminar. In: LEAL, I. R. \& SILVA, J. M. C. (Ed.). Ecologia e conservação da caatinga. Recife: Ed. Universitária/UFPE. pp. 695-715.

OLIVEIRA FILHO, A. T.; JARENKOV, J. A.; RODAL, M. J. N. (2006) Floristic relationships of seasonally dry forests of eastern South America based on tree species distribution pattern. In: PENNINGTON, R. T.; LEWIS, G. P.; RATTER, J. A. Neotropical savannas and seasonally dry forests. Boca Raton (EUA): CRC Press. pp. 159-190.

Ministério da Previdência SOCIAL (MPS) Estatísticas municipais 2000 a 2012. Disponível em: <http://www.previdencia.gov.br/estatisticas-municipais-2000-a2010>. Acessado em: 20 set. 2013. 
PARAÍBA (2011). Plano de Ação Estadual de Combate à Desertificação e Mitigação dos Efeitos da Seca PAE/PB. João Pessoa: Secretaria de Estado dos Recursos Hídricos, do Meio Ambiente e da Ciência e Tecnologia/SUDEMA. Disponível

em:

www.aesa.pb.gov.br/trabalhosTecnicos/trabalhos/arquivos/Relatorio_Prelimiar_15_ PAE_PB_15_SET_2011.pdf. Acessado em: 23 jan. 2014.

PENNINGTON, R. T.; PRADO, D. A.; PENDRY, C. (2000) Neotropical seasonally dry forests and Pleistocene vegetation changes. J. Biogeogr., v. 27. pp. 261-273.

PETERSEN, P.; SILVEIRA, L.; ALMEIDA, P. (2002) Ecossistemas naturais e agroecossistemas tradicionais no Agreste da Paraíba: uma analogia socialmente construída e uma oportunidade para a conversão agroecológica. In: SILVEIRA, L.; PETERSEN, P.; SABOURIN, E (Org.). Agricultura familiar e agroecologia no semiárido: avanços a partir do Agreste da Paraíba. Rio de Janeiro: AS-PTA. pp. 13122.

SANTOS, R. M.; OLIVEIRA-FILHO, A. T.; EISENLOHR, P. V.; QUEIROZ, L. P.; CARDOSO, D. B. O. S.; RODAL, M. J. N. (2012) Identity and relationships of the Arboreal Caatinga among other floristics units of seasonally dry tropical forests (SDTFs) of northeastern and central Brazil. Ecol. Evol., 2 (2), february. pp. 409-428. SIDERSKY, P. e SILVEIRA, L. M. (1998). Experimentar com agricultores; a experiência da AS-PTA na Paraíba. Recife: AS-PTA.

SIMÕES, D. A.; SANTOS, D. C.; DIAS, F. M. Introdução da palma forrageira no Brasil. MENEZES, R. S. C.; SIMÕES, D. A.; SAMPAIO, E. V. S. B. (Ed.). (2005) A palma no Nordeste do Brasil: conhecimento atual e perspectivas de uso. Recife: Ed. Universitária/UFPE. pp. 13-26.

SOARES, J. G. G.; GUIMARÃES FILHO, C.; SALVIANO, L. M. C. (2006) Composição botânica da dieta de caprinos em vegetação típica de caatinga sob diferentes taxas de lotação. Petrolina: EMBRAPA, Boletim de Pesquisa e Desenvolvimento.

SOUSA, R. F. (2007) Terras agrícolas e o processo de desertificação em municípios do semiárido paraibano. $180 \mathrm{f}$. Tese (Doutorado dirigido por Max Prestes) - Programa de Pós-Graduação em Engenharia Agrícola, Universidade Federal de Campina Grande. Campina Grande.

SOUZA. B. I.; SUERTEGARAY, D. M. A.; LIMA, E. R. V. Políticas Públicas, uso do solo e desertificação nos Cariris Velhos (PB/Brasil). Scripta Nova, Barcelona, 10 de enero de 2010, vol. XIV, $\mathrm{n}^{\mathrm{o}}$ 311. Disponível em: <http://www.ub.es/geocrit/sn/sn-311.htm.>. Acessado em: 12 fev. 2014.

SOUZA. B. I.; SUERTEGARAY, D. M. A.; LIMA, E. R. V. (2011) Evolução da desertificação no Cariri paraibano a partir da análise das modificações na vegetação. Revista Geografia, Rio Claro, janeiro a abril, v. 36. pp. 193-207. Disponível em: <http://www.periodicos.rc.biblioteca.unesp.br/index.php/ageteo/index.>. Acessado em: 14 fev. 2014. 
SUERTEGARAY, D. M. A. (2001) Espaço Geográfico uno e múltiplo. Scripta Nova, Barcelona, 15 de julio, $\mathrm{n}^{\circ}$ 93. Disponível em: <http://www.ub.edu/geocrit/sn93.htm.>. Acessado em: 20 fev. 2014.

Data de submissão: 05/05/2015.

Data de aceite: 29/08/2015. 